\title{
AN APPARATUS FOR THE STUDY OF
}

THERMOLUMINESCENCE FROM MINERALS

By G. E. Ashby and R. C. Kellagher

Trace Elements Investigations Report 691

UNIIEDD STATES DEPARTMENT OF THE INTERIOR GEOLOGICAL SURVEY 
$(200)$
Terr
$n 0.691$

Geology and Mineralogy

UNITED STATES DEPARTMENT OF THE INTERIOR

GEOLOGICAL SURVEY

AN APPARATUS FOR THE STUDY OF THERMOLUMINESCENCE FROM MINERALS*

By

G. E. Ashby and R. C. Kellagher

JuIy 1957

Trace Elements Investigations Report 691

This preliminary report is distributed without editorial and technical review for conformity with official standards and nomenclature. It is not for public inspection or quotation.

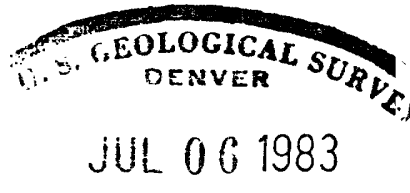

An LIBRARY

*This report concerns work done on behalf of the Division of Research of the U. S. Atomic Energy Commission. 
USGS - TEI-69I

GEOLOGY AND MINERALOGY

Distribution

No. of copies

Division of Raw Materials, Albuquerque ..................... I

Division of Riw Materials, Austin .......................... I

Division of Raw Materials, Casper ........................... 1

Division of Raw Materials, Denver ........................... I

Division of Raw terials, Rapid City ...................... I

Division of Raw Materials, Salt Lake City .................... I

Division of Raw Materials, Spokane ........................ I

Division of Raw Materials, Washington ...................... 3

Division of Research, Washington ........................ 1

Exploration Division, Grand Junction Operations Office .......... I

Grand Junction Operations Office ......................... 1

Technical Information Service Extension, Oak Ridge ............6

U. S. Geological Survey:

Foreign Geology Branch, Washington ....................... 1

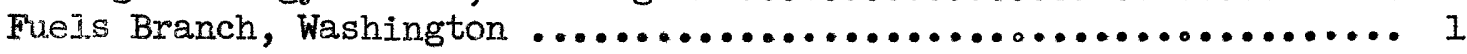

Geochemistry and Petrology Branch, Washington ................ 15

Geophysics Branch, Washington ........................... I

Mineral Deposits Branch, Washington ...................... 2

P. C. Bateman, Menlo Park ................................ I

A. L. Brokaw, Grand Junction ............................ I

N. M. Denson, Denver ................................... I

R. L. Griggs, Albuquerque ............................. I

W. R. Keefer, Laramie .................................. I

E. W. Lakin, Denver ................................... 1

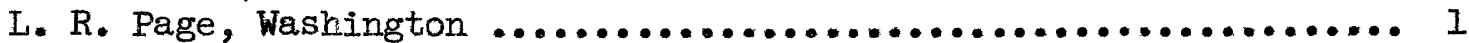

P. K. Sims, Denver ................................. 1

Q. D. Singewald, Beltsville ........................... I

A. E. Weissenborn, Spokane ............................ 1

TEPCO, Denver ........................................ 2

TEPCO, RPS, Washington, (including master) $\ldots \ldots \ldots \ldots \ldots \ldots \ldots \ldots \ldots$ 
CONTENTS

Page

Abstract $\ldots \ldots \ldots \ldots \ldots \ldots \ldots \ldots \ldots \ldots \ldots \ldots \ldots \ldots \ldots \ldots \ldots \ldots \ldots \ldots \ldots \ldots \ldots \ldots \ldots \ldots$

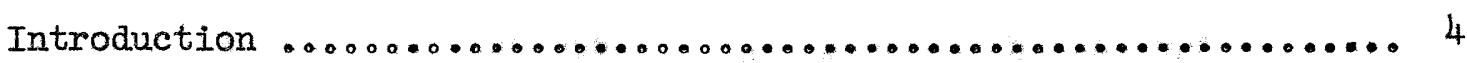

Description $\ldots \ldots \ldots \ldots \ldots \ldots \ldots \ldots \ldots \ldots \ldots \ldots \ldots \ldots \ldots \ldots \ldots \ldots \ldots \ldots \ldots$

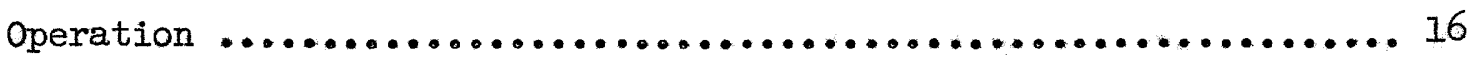

Performance $\ldots \ldots \ldots \ldots \ldots \ldots \ldots \ldots \ldots \ldots \ldots \ldots \ldots \ldots \ldots \ldots \ldots \ldots \ldots \ldots \ldots \ldots \ldots \ldots \ldots$

References $\ldots \ldots \ldots \ldots \ldots \ldots \ldots \ldots \ldots \ldots \ldots \ldots \ldots \ldots \ldots \ldots \ldots \ldots \ldots \ldots \ldots \ldots \ldots \ldots$

\section{IILUSTRATIONS}

Figure 1. Thermoluminescence apparatus .................... 8

2. An exploded view of the base of the thermoluminescence apparatus $\ldots \ldots \ldots \ldots \ldots \ldots \ldots \ldots \ldots \ldots \ldots \ldots \ldots \ldots \ldots \ldots \ldots \ldots \ldots$

3. Block diagram of the electrical circuits ............13

4. Wiring diagram of the high voltage supply, photomultiplier tube, and microammeter ............... 14

5. A typical glow curve for calcite obtained after

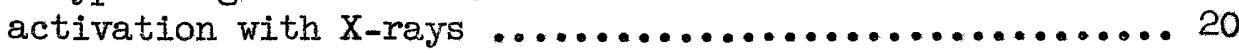

6. Typical saturation and decay curves for calcite. X-ray irradiation was terminated after 428 minutes .......... 21

7. The thermoluminescence apparatus mounted on an X-ray diffraction camera track 
AN APPARATUS FOR THE STUDY OF THERMOLUMINESCENCE FROM MINERAIS

By G. E. Ashby and R. C. Kellagher

\section{ABSTRACT}

An apparatus has been constructed to record the thermoluminescence of a mineral in the form of a powder or a single crystal at temperatures from $-100^{\circ} \mathrm{C}$ to $+400^{\circ} \mathrm{C}$. Glow curves are obtained by heating the sample at a constant rate and recording the intensity of thermoluminescence as a function of temperature. The apparatus has provision for the irradiation of the sample with X-rays or ultraviolet light and for measurement of the induced luminescence during any part of the experiment. Upon termination of the irradiation the measurement of the luminescence can be continued at any desired temperature, and rapidly decaying phosphorescence can be detected. In all these experiments the sample remains undisturbed, and the problems associated with the heterogeneity of the sample are thus reduced.

\section{INTRODUCTION}

Recent studies (Daniels and Saunders, 1951; Daniels, Boyd, and Saunders, 1953; Saunders, 1953; Pitrat, 1956; and Zeller, Wray, and Daniels, 1957) have shown that a study of the thermoluminescence of minerals and rocks can provide information applicable to problems in stratigraphy, geologic age determination, and geothermometry. It has been established that some minerals have electron traps that are the result of imperfections in the crystal structure such as vacant lattice sites, interstitial atoms, 
foreign atoms in either interstitial or substitutional positions, and dislocations (Seitz, 1952), and that these imperfections are a function of the environmental conditions during crystallization and the subsequent history of the mineral. Excited electrons produced by ionizing radiations interacting with the mineral are trapped by the lattice imperfections. The time that the trapped electrons exist in a metastable energy state depends on the binding energy of the trap and the temperature of the solid. Some electrons exist in a metastable state throughout geologic history and can be released at a future time by the application of heat. A solid is termed thermoluminescent if the electrons detrapped by heat make energy transitions that yield wavelengths in the visible region.

Several designs of apparatus for performing thermoluminescence experiments have been described. Randall and Wilkins (1945) obtained glow curves from sample material brushed on the prepared surface of an electrically heated copper box. A thin layer of sample is spread on the surface of the box using a slight smear of glycerol as a binder. A thermocouple is soldered to the same surface and a helical coil of resistance wire is arranged within the box to function as a heater. The entire apparatus is cooled by liquid air. When the sample reaches the desired temperature, it is activated by irradiation with the light from a mercury arc until the electron traps are filled. After activation of the sample the box is removed from the coolant and placed in the dark before an electron multiplier tube. The heater is then energized and the sample is heated at a constant rate to produce luminescence. A glow curve is obtained by recording the intensity of the luminescence as a function of temperature. 
Daniels and Saunders (1951) described a similar apparatus in which glow curves are obtained from room to incandescence temperatures from a sample spread on the surface of an electrically heated silver block. Sample materials are reactivated by X-ray, gamma-ray, or ultraviolet light irradiation before being placed in the apparatus. In a later design by Daniels, a tungsten strip is substituted for the silver block in order to obtain a higher heating rate and increased sensitivity. Heckelsberg (1951) has described an apparatus that permits a sample to be reactivated at liquid air temperatures with X-rays, and that will yield glow curves from liquid air to room temperatures.

In the present paper an apparatus is described that will record the thermoluminescent properties of a sample in the form of a powder or single crystal, at temperatures from $-100^{\circ} \mathrm{C}$ to $+400^{\circ} \mathrm{C}$ at either fast or slow controlled heating rates. It has provision for the irradiation of the sample with X-rays or ultraviolet light and for the measurement of the induced luminescence during any part of the experiment. Upon termination of the irradiation the measurement of the luminescence can be continued and rapidly decaying phosphorescence can be detected. In all of these experiments the sample remains undisturbed and the problems associated with the heterogeneity of the sample are thus reduced.

We wish to acknowledge our discussions of the problems in measuring thermoluminescence with C. L. Christ, U. S. Geological Survey, and Farrington Daniels, University of Wisconsin. The apparatus was constructed by E. I. Curtis and J. F. Abell of the U. S. Geological Survey. This report concerns work conducted by the U.S. Geological survey on behalf of the Division of Research of the U. S. Atomic Energy Commission. 


\section{DESCRIPTION}

The thermoluminescence apparatus consists of an electrically heated sample stage positioned under a photomultiplier tube in a light-and gas-tight cylinder (fig. I). This cylinder is an assembly of three individual units, a barrel to house the photomultiplier tube, a cap containing the tube-socket assembIy, and a base containing the heater. Mounting studs on the flange of the heater unit and on the upper flange of the barrel are used to position the units for assembly. Ring seals between the flanges form light- and gas-tight barriers when the unit is assembled. This construction permits easy access to the internal parts of the apparatus and enables the operator to change samples with a minimum of effort.

The largest unit, the barrel, is a machined brass cylinder $81 / 2$ in. long with a diameter of $31 / 4$ in. and has a $3 / 4$ by $1 / 4$ in. flange on each end. Inside the barrel is a brass diaphragm $2 \mathrm{I} / 4 \mathrm{in}$. from the bottom face. The diaphragm has a l-in. diameter aperture with a circular shutter that can be opened or closed from outside the barrel by means of a knob.

A gas manifold containing eight ports is at the base of the barrel. Its purpose is to direct a flow of inert gas onto the sample stage. Gas is introduced into the manifold through a fitting soldered into the barrel wall and controlled by adjusting an exhaust valve in the wall of the upper chamber. 


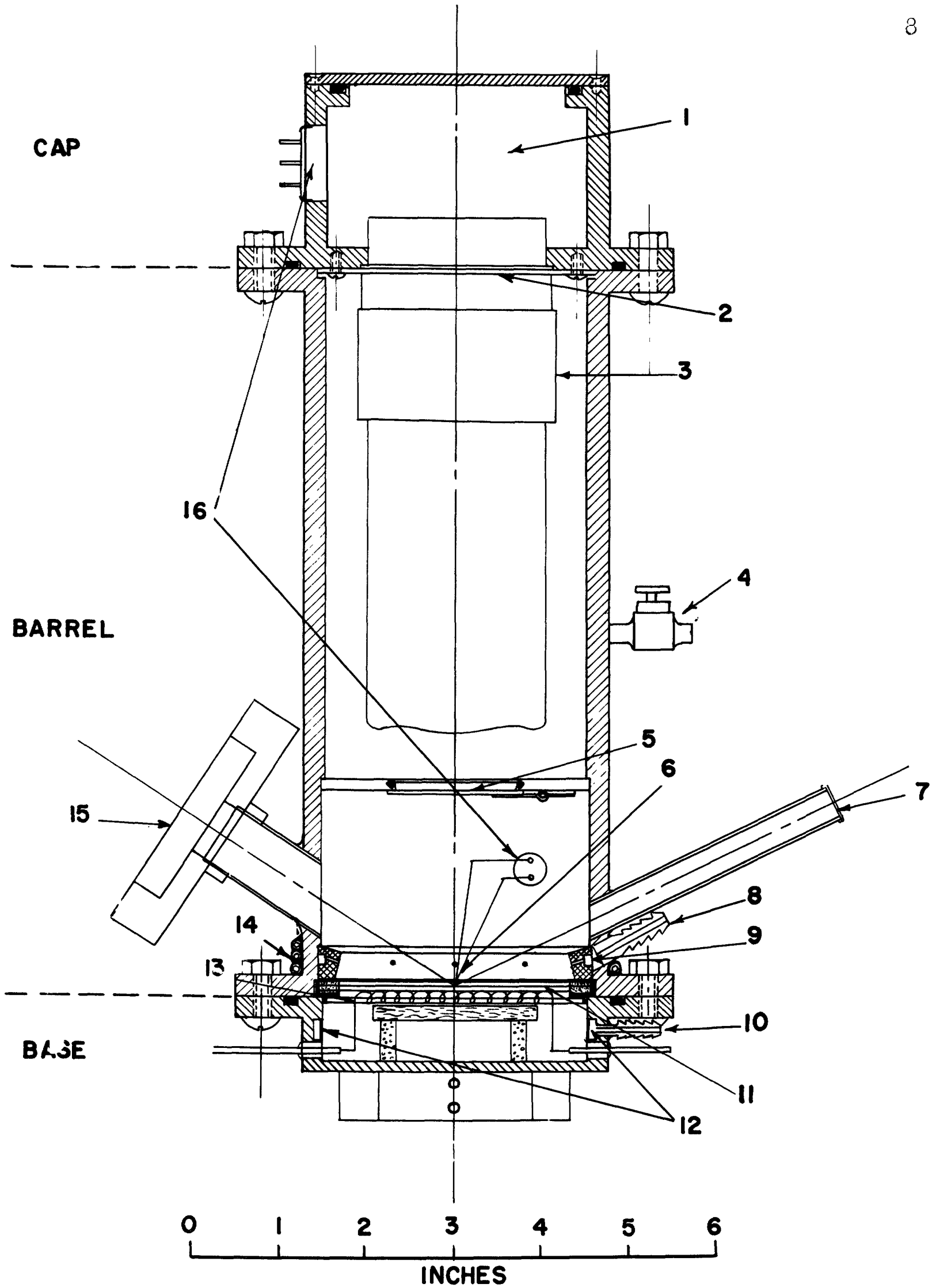

Figure 1.--Thermoluminescence apparatus: (1) space for electrical circuits, (2) tube socket, (3) photomultiplier tube, (4) gas exhaust valve, (5) shutter, (6) thermocouple, (7) X-ray collimator, (8) gas inlet, (9) gas manifold, (10) water connections, (11) sample stage, (12) water conduit, (13) heating element, (14) water cooling coils, (15) filter adapter, and (16) ceramic plugs for electrical connections. 
A brass tube of $3 / 8$-in. inside diameter is soldered into the side of the lower chamber at an angle of $26^{\circ}$ with the axis of the barrel at a point $I$ ineh above the base. This tube acts as an X-ray collimator and permits irradiation of the center of the stage with X-rays. The tube is closed at the outer end with a beryllium foil $0.007-$ in. thick to make it light-and gas-tight. This foil is transparent to X-rays.

Opposite the X-ray collimator and similarly mounted is a tube of 3/4-in. inside diameter that is used principally to allow light transmission to and from the sample through the barrel wall. This tube is also useful for final positioning of samples and adjusting thermocouples before an experimental run. An adapter, fitted to the tube, will accommodate one or more 2-by-2-in. light filters. These filters are useful for restricting the wavelengths of the light that strike the sample and for spectral analysis of the thermoluminescent light. The tube is normally closed with a black rubber stopper when light from the room cannot be tolerated. Temperature measurements are made with two chromel-alumel thermocouples in the sample chamber. The leads of the thermocouples are connected to a terminal strip on the outside surface of the barrel and enter the sample chamber through a light-and gas-tight ceramic plug mounted in the barrel wall. The ceramic plug and terminal strip have provision for additional leads for electrical conductivity measuring apparatus. In addition, the barrel is water-cooled to protect the photomultiplier tube and ring seals from damage. The water flows through a three-turn coil soldered around the base of the barrel. 
The cap or photomultiplier tube socket assembly holds the tube socket in position and contains part of the electrical circuits for the tube. The cap has a brass collar, $31 / 4 \mathrm{in}$. in diameter by $21 / 4$ in. long, with a $3 / 4$ by $1 / 4$ in. flange on one end. The socket is centra1ly mounted with the tube side of the socket flush with the flange surface and held in position by two screws. A distance of approximately $11 / 2 \mathrm{in}$. extends above the socket to accommodate electrical circuits. This space is closed by a cover plate and sealed with a ring seal. A ring seal is also placed in the flange to seal the connection between this assembly and the barrel. A light- and gas-tight ceramic plug soldered in the collar allows electrical connections to be made from the tube socket to an external terminal strip.

The base (fig. 2) consists of the heating element, sample stage, and a housing. A nichrome-V wire spiral of 50 ohms resistance wound over a silica plate 2 by 2 by $1 / 8$ in. serves as the heating element. The plate is notched to position the winding and is designed to space ten spirals across the surface. Ceramic beads are placed on the windings to prevent shorting between adjacent spirals and between the windings and the silver stage.

A sample stage, composed of a silver disk 0.02 in. thick and $23 / 4$ in. in diameter, is mounted in a brass ring between asbestos gaskets. The ring positions the stage over the heating element and forms a light-tight seal between the heating element and photomultiplier tube. A silver ring with a diameter of $7 / 8$ in., a wall height of $1 / 8 \mathrm{in.,}$ and a thickness of 1/32 in. is silver-soldered to the center of the stage to retain the sample in position under the photomultiplier tube. 


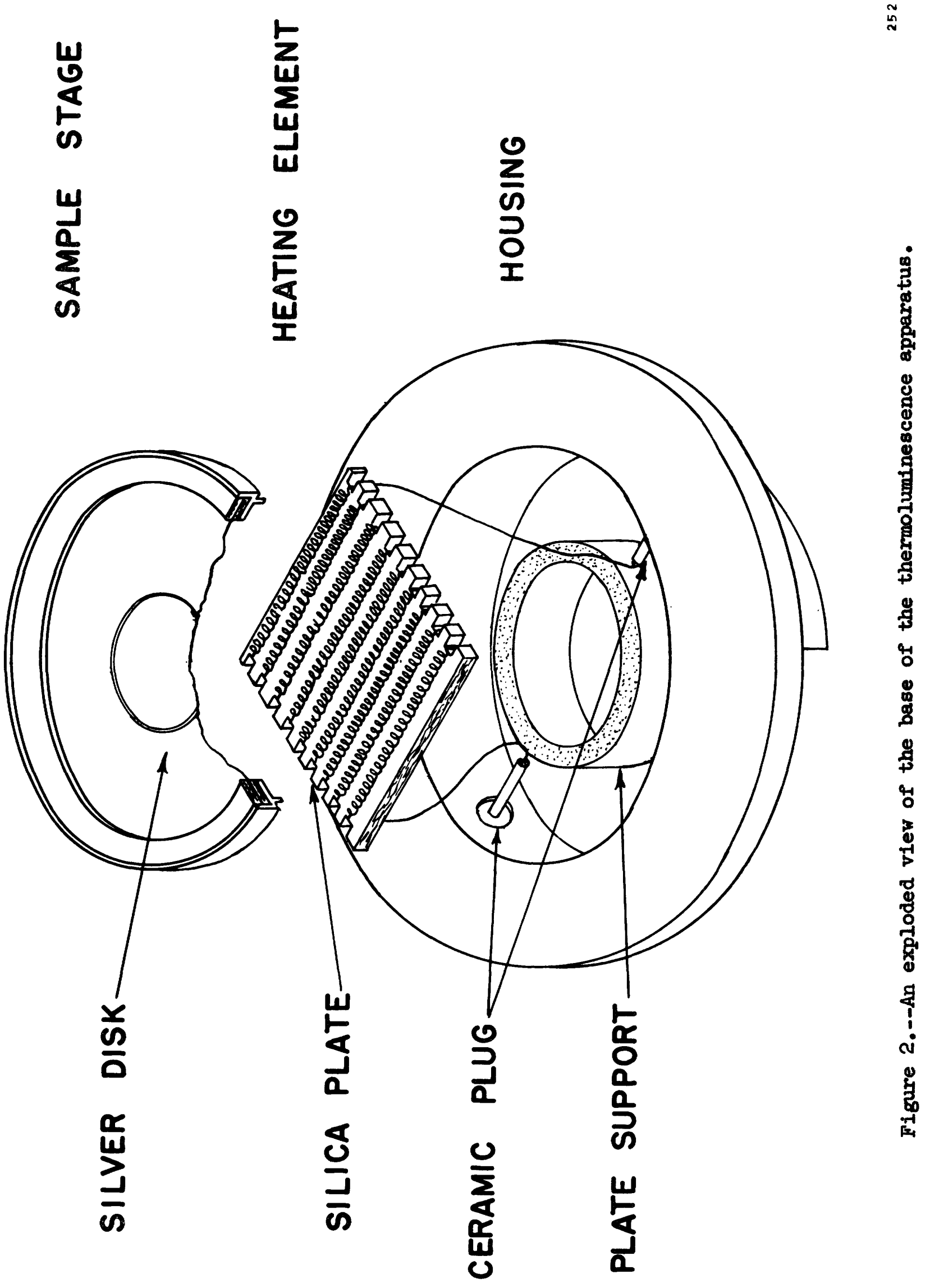


The heating element is contained in a flanged brass cup $7 / 8$ in. deep and 3 in. in diameter and is positioned with the upper surface of the element flush with the cup rim. A silver sample stage is placed. above this surface and in contact with the ceramic beads on the element. A water conduit in the wall of the housing surrounds the element and keeps the wall of the cup at approximately room temperature while the heater is in operation. Electrical connections for the element are made through gas-tight ceramic plugs. The base of the heater has been machined to fit a standard camera track of an X-ray diffraction unit.

Controlled low temperatures of $-100^{\circ} \mathrm{C}$ to room temperature are obtained in the sample chamber by a nitrogen cooling system. The lower part of the apparatus is immersed in liquid nitrogen to obtain a $-100^{\circ} \mathrm{C}$ temperature. When a higher temperature is desired, the heating element is energized and controlled with a 0 to 115 volt autotransformer.

Electrical circuits for the apparatus are shown in a block diagram, (fig. 3) and in a wiring diagram (fig. 4). High voltage for the operation of the photomultiplier tube is supplied by a battery pack containing twenty-four 45-volt batteries connected in series. Selected voltages from 855 volts to 1080 volts, in increments of 45 volts, are supplied to the tube through a six-position selector switch on the power supply chassis. A conventional voltage divider connected to this high voltage supply provides the voltages necessary for each dynode of a 5819 photomultiplier tube. 
13

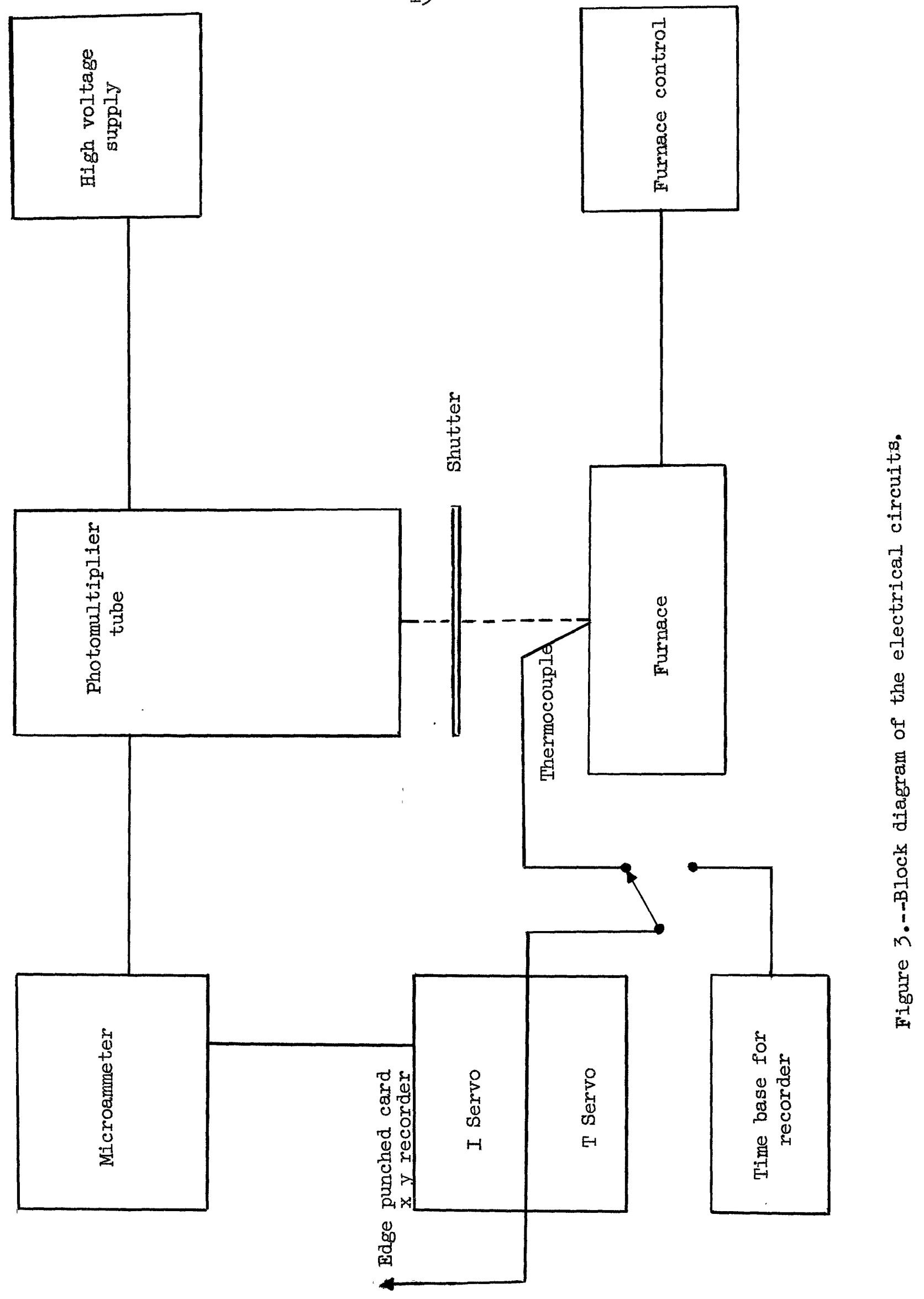



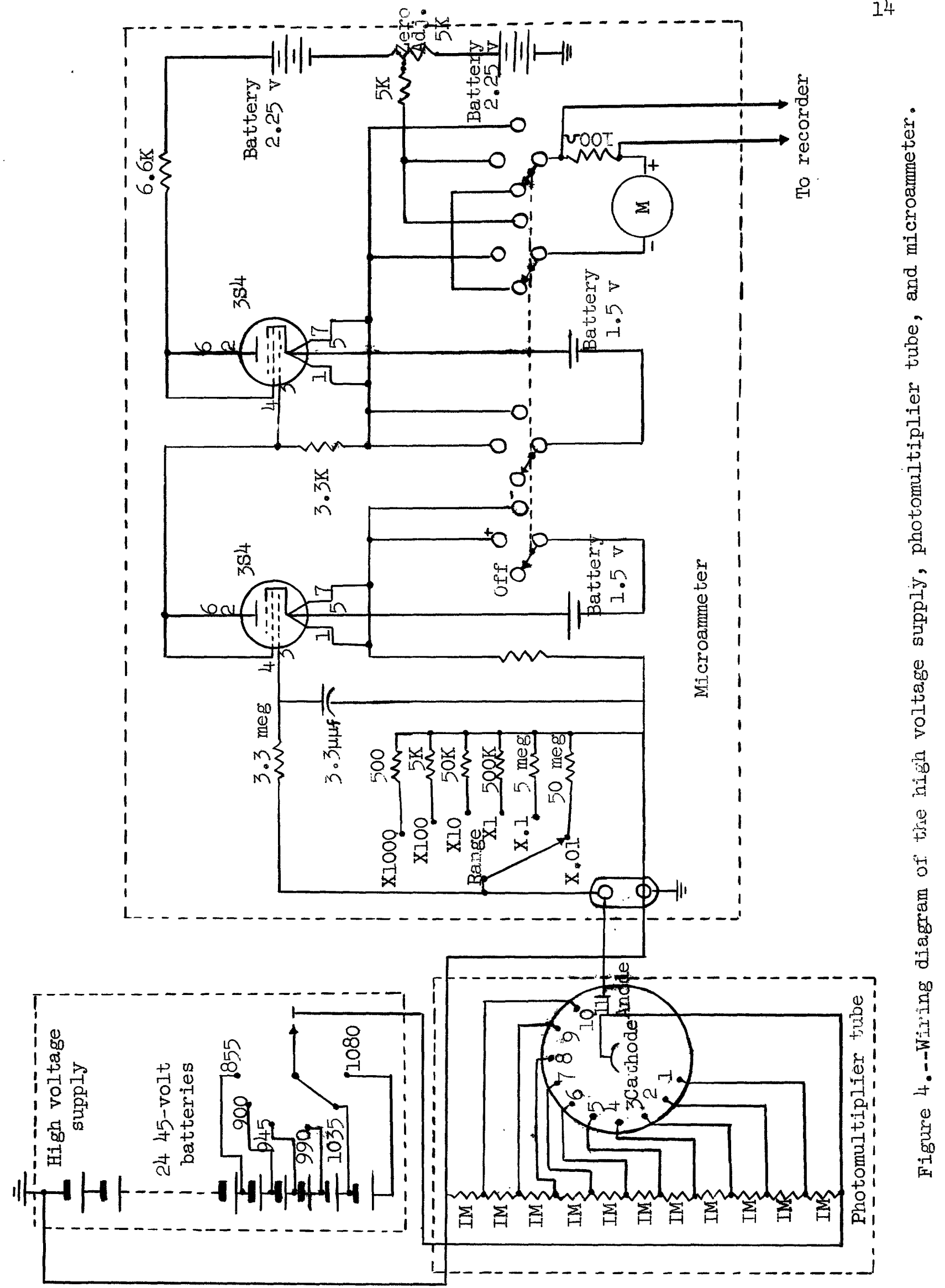
The photomultiplier tube develops an anode current that is directly proportional to the amount of light striking the photosensitive cathode. Current from the anode is measured by a modified ultrasensitive directcurrent microammeter. An anode current of 0.01 microamperes is sufficient to give full scale deflection on the meter of this instrument with an overall accuracy of \pm 5 percent. Full scale currents of $0.1,1.0,10,100$, and 1000 microamperes can also be selected with a range switch.

An output signal suitable for a strip-chart recorder is obtained from the microammeter by a slight modification of the circuit. A 100-ohm resister in series with the meter develops approximately a 10-millivolt voltage drop at full scale on all ranges. This voltage drop is used as an output signal to the recorder.

The recorder consists of two servo units: a pen-drive unit operating from the output signal of the microammeter, and a chart-drive unit operating from either a thermocouple or time-base generator. Both of these servos operate on the principle of a self-balancing potentiometer. In each, a servo motor rotates a potentiometer to produce a direct-current voltage that exactly cancels the applied direct-current signal, and thus determines the position of the writing pen or chart. These servo units have a fullscale sensitivity of 10 millivolts with a 2.5 second full-scale response time.

The chart-servo unit can be connected to either a thermocouple signal or time signal by a selector switch. At the thermocouple setting of the switch a chromel-alumel thermocouple is connected in series with a voltage dividing resistor. A voltage change produced by the thermocouple will move the chart with respect to the pen an amount proportional to the change. 
With the switch in this position and with the thermocouple in contact with the sample, current from the photomultiplier is displayed on the chart as a function of the temperature of the sample. The scale factor of the chart may be adjusted to any value from $5^{\circ} \mathrm{C}$ to $20^{\circ} \mathrm{C}$ per division by the voltage dividing resistor.

A voltage varying as a linear function of time is introduced into the chart-servo from the time-base generator when the selector switch is on the "time" setting. This generator consists of a 10-turn potentiometer with a wiper driven by a l/2-rpm synchronous motor. By adjusting the voltage supplied to the potentiometer, the rate of change of the voltage output of the generator can be varied from $1 / 2$ millivolt to 5 millivolts per minute. Variable chart speeds can be obtained in this manner. With the switch on the "time" setting, the current from the anode of the photomultiplier is displayed as a function of time.

The photomultiplier, microammeter, and time-base generator are all powered by batteries in order to reduce the pickup of stray currents and thus to increase the stability of the servo system.

The charts for the recorder are printed on cards 12 inches long. With the chart in this form, the drive sprocket holes along its edge may be punched and the chart indexed and sorted as an edge-punched card.

\section{OPERATION}

The apparatus is designed to perform three basic thermoluminescence experiments: (l) to heat a sample at a constant rate and measure the light emission as a function of temperature--that is, to produce the glow curve; (2) to irradiate the sample at a known temperature and measure the light 
emission as a function of time--that is, to produce the saturation curve; and (3) to measure the phosphorescence from a sample as a function of time--that is, to produce the decay curve. The procedure for operating the apparatus varies with each type of experiment. In all experiments, the method of mounting the sample, the positioning of the thermocouple, and adjustment of the light recording equipment is identical. The sample, a specimen of mineral or rock in the form of a powder or thin slab is mounted in an area of $7 / 8$ in. diameter at the center of the stage. When the barrel is assembled to the heater unit, the thermocouple is positioned on the surface of the sample. Observation and manipulation of the thermocouple can be made through the larger tube in the barrel wall to insure contact with the sample.

The adjustment of the light recording equipment consists of: (1) selecting a voltage for the photomultiplier tube, (2) selecting the range setting for the microammeter, (3) zeroing the microammeter and penservo system. The photomultiplier tube is usually operated at 855 volts, but occasionally higher voltages are used when increased sensitivity is desired. In selecting a range setting a value should be used that will make the maximum response during the experiment approach the full-scale value of the microammeter. This selection is, of course, impossible in most experiments without prior knowledge of the result. The operator can, however, from experience with the behavior of different types of samples predict approximately the range setting for the experiment. In general, the setting is usually $0.1,1$, or 10 microamperes. The microammeter and pen servo are adjusted to zero with the apparatus assembled and the shutter in the closed position. A zero-adjusting resistor is used to 
balance the bridge cireuit of the microammeter. The pen-servo system is adjusted to give a zero pen position on the chart when the microammeter is at zero.

After mounting the sample and adjusting the circuits the equipment is ready for determination of either a glow curve, saturation curve, or decay curve. To obtain a glow curve, the sample is heated at a constant rate by controlling the voltage supplied to the heater with a 0 to 115 volt autotransformer. Before the sample is heated, the chart is adjusted to show the initial temperature of the sample. This temperature is obtained. by comparing the voltage developed by the thermocouple on the sample to that developed by a thermocouple at $0^{\circ} \mathrm{C}$. The glow curve is recorded with the thermoluminescence intensity expressed as the ordinate and the sample temperature as the abscissa (fig. 5).

The saturation curve is obtained by recording the fluorescence intensity as a function of the time of irradiation by $\mathrm{X}$-rays or light (fig. 6). When X-ray irradiation is desired, the apparatus is mounted on a standard camera track of an X-ray diffraction unit (fig. 7 ) so that the $\mathrm{X}$-ray beam passes through the X-ray collimator in the barrel wall and strikes the sample. As the photomultiplier is only sensitive to wavelengths between 3000 and $6600 \mathrm{~A}$, it will not record X-ray photons. When ultraviolet light is used for excitation, the apparatus is positioned so that the light source is adjacent to the filter adapter. Filters are selected and mounted in the adapter that will transmit only the desired wavelengths to the sample. In addition, a filter can be placed on the diaphragm between the photomultiplier and the stage to absorb reflected light from the sample stage. 


\section{PERFORMAIVCE}

The following data illustrate the performance of the apparatus:

(I) Maximum constant heating rate: $2.7^{\circ} \mathrm{C}$ per second.

(2) Optimum maximum temperature of stage: $400^{\circ} \mathrm{C}$.

(3) Average cooling time from $400^{\circ} \mathrm{C}$ to room temperature: $21 / 2$ minutes.

(4) Optimum minimum temperature of stage: $-100^{\circ} \mathrm{C}$.

(5) Maximum light sensitivity (at $4900 \mathrm{~A}$ ): $4.2 \times 10^{-12}$ lumens per chart division.

(6) Noise at maximum sensitivity: 5.0 chart division or $2.0 \times 10^{-11}$ lumens.

(7) Response time of recorder: 3.0 seconds for full scale on either servo.

(8) Accuracy of microammeter: \pm 5 percent of full scale.

(9) Accuracy of recorder: \pm 1 percent of full scale.

The most probable sources of error in the measurement of the temperature of the sample are in the heat loss through the thermocouple leads and variation in contact between the thermocouple and sample. If these errors are negligible and the voltage at the ends of the thermocouple leads is a true measure of the sample temperature, then the chart will indicate the temperature to within $\pm 2^{\circ} \mathrm{C}$. 


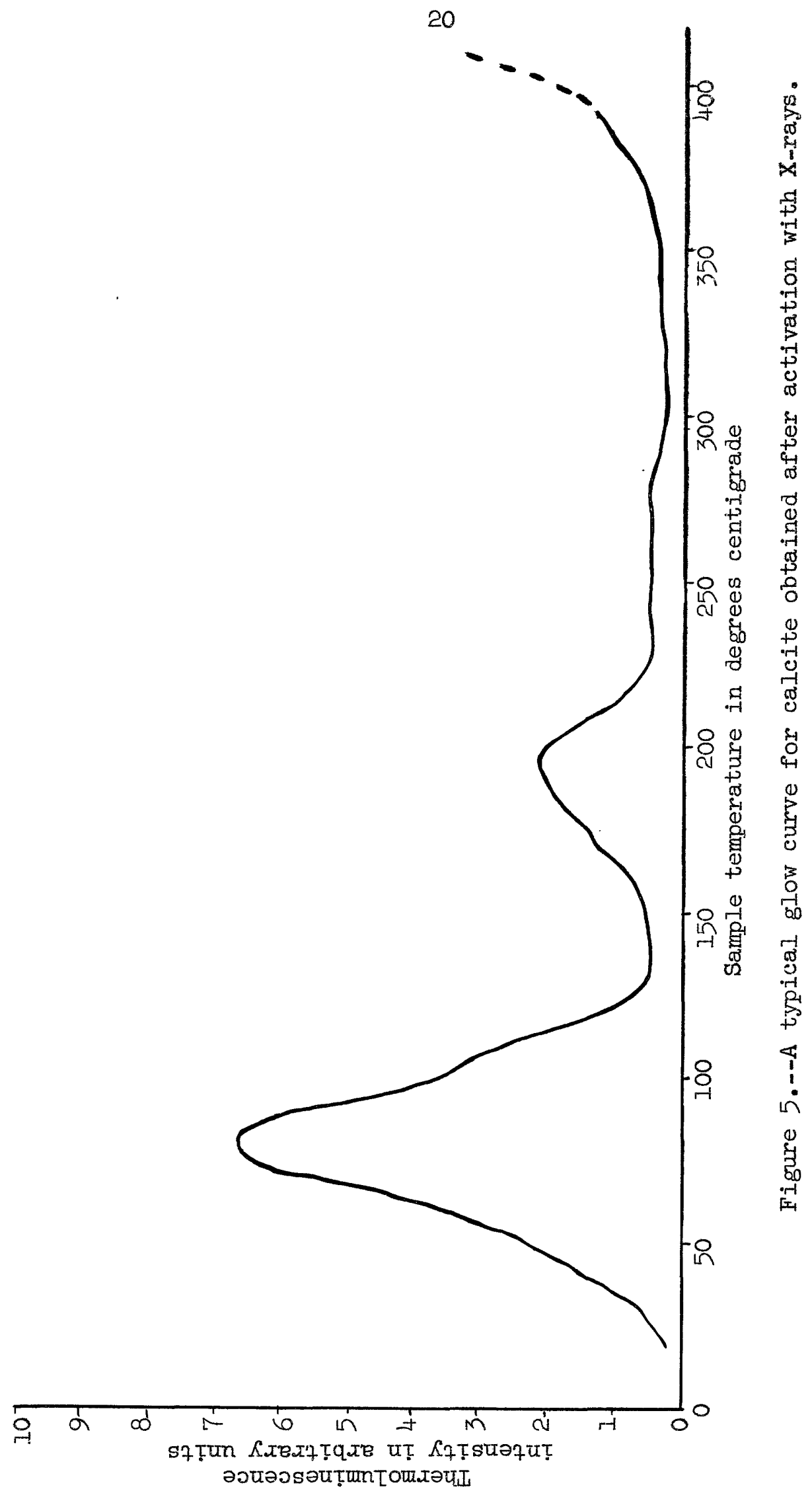




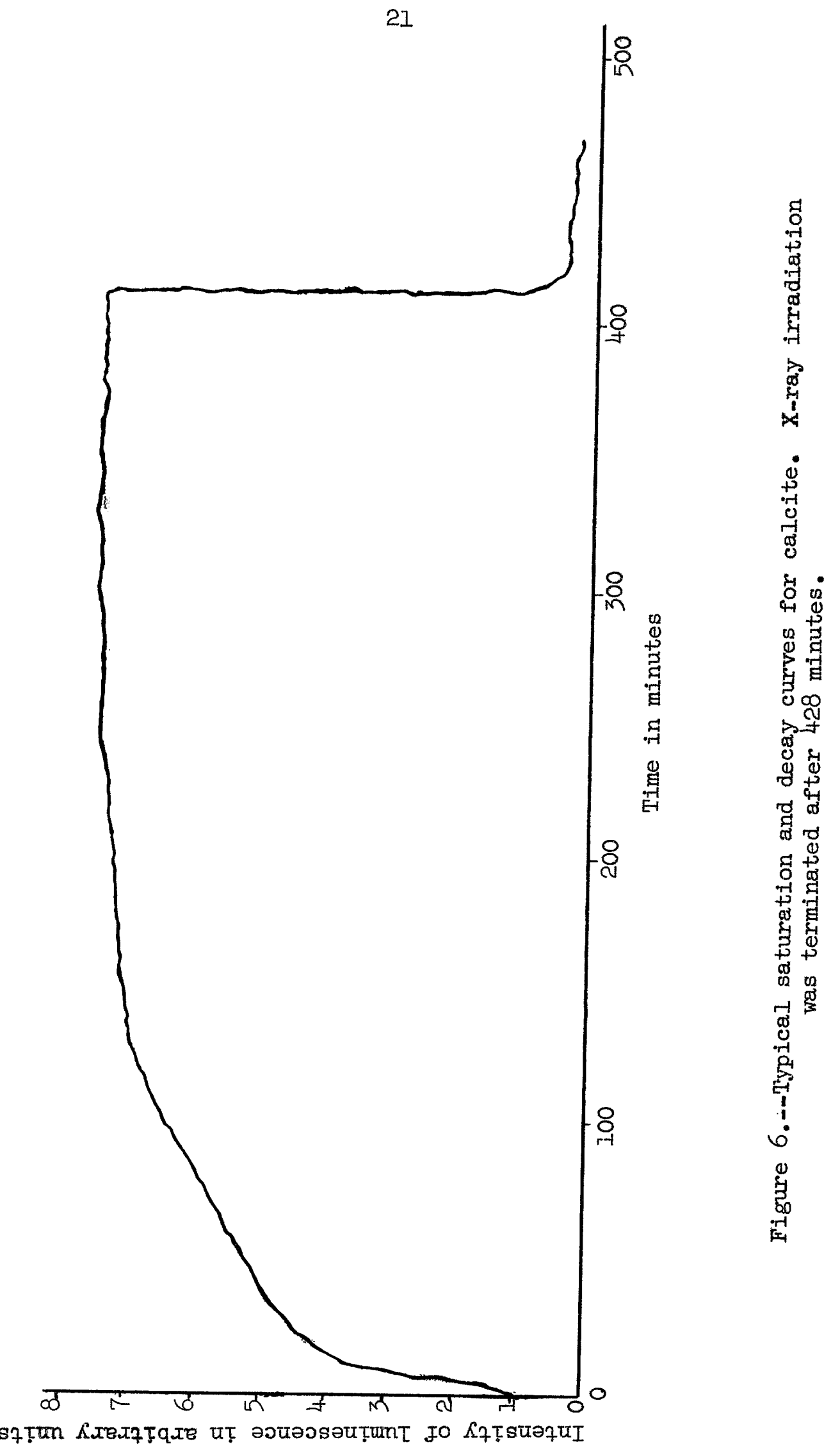




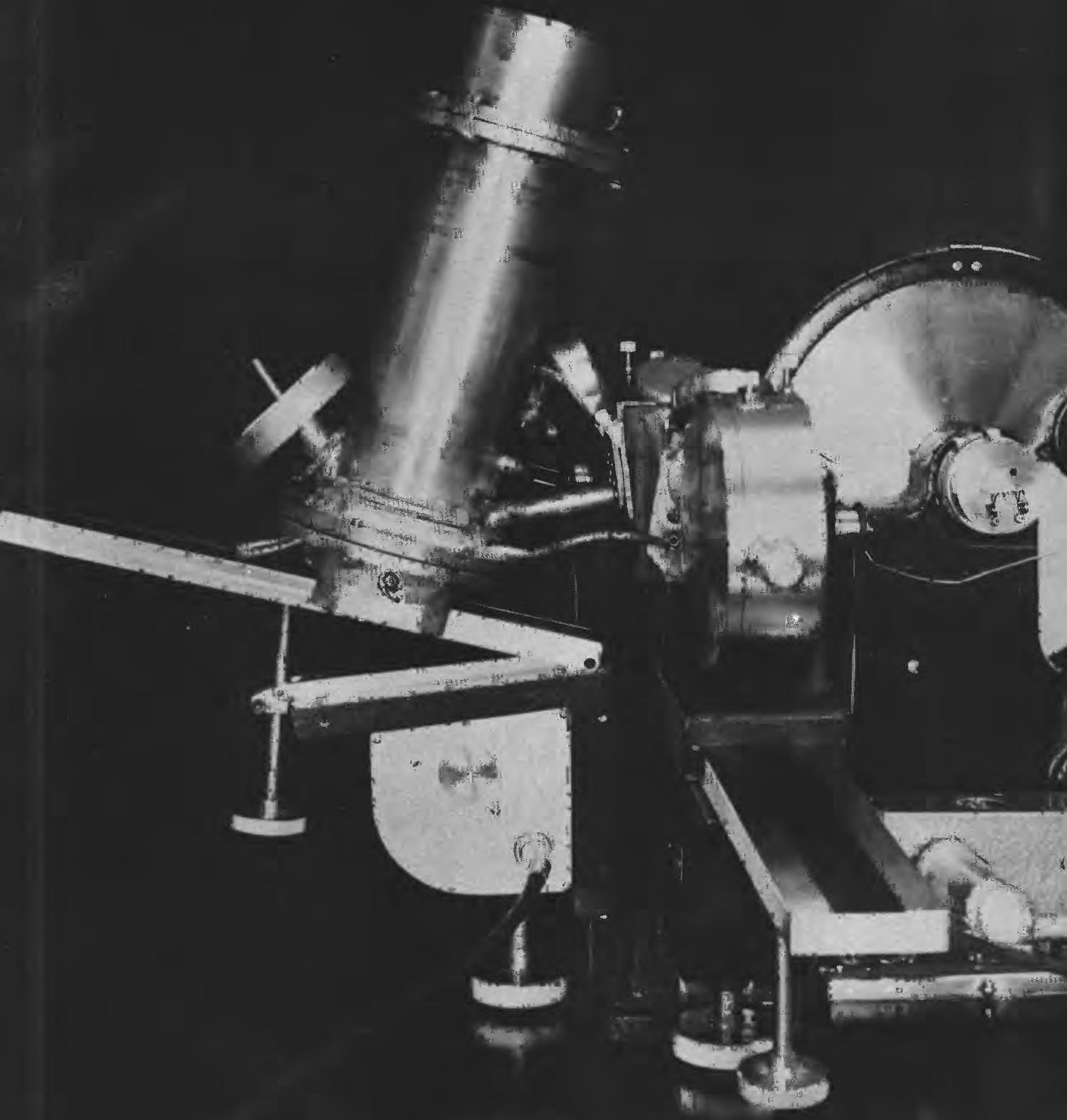

Figure 7.--The thermoluminescence apparatus mounted on an X-ray 


\section{REFERENICES}

Daniels, Farrington, Boyd, C. A., and Saunders, D. F., 1953, Thermoluminescence as a research tool: Science, v. 117, p. 343-349.

Daniels, Farrington, and Saunders, D. F., and others, 1951, The thermoIuminescence of crystals--Final report: U. S. Atomic Energy Comm. AECU-1583, 26 chapters. [Microcard copy on file in U. S. Atomic Energy Comm. depository libraries.7.

Heckelsberg, I. F., 195I, Thermoluminescence and related properties of the alkali halides, Chapter 5, p. 1-29, in Daniels, Farrington, and Saunders, D. F., and others, The thermoluminescence of crystals-Final report: U. S. Atomic Energy Comm. AECU-1583, 26 chapters. Microcard copy on file in U. S. Atomic Energy, Comm. depository libraries. 7

Pitrat, C. W., 1956, Thermoluminescence of Iimestones of Mississippian Madison group in Montana and Utah: Am. Assoc. Petroleum Geologists Bull., v. 40, p. 943-952.

Randa11, J. T., and Wilkins, M. H. F., 1945, Phosphorescence and electron traps. I. The study of trap distributions: Royal Soc. London Proc. A, v. 184, p. 366-389.

Saunders, D. F., 1953, Thermoluminescence and surface correlation of limestones: Am. Assoc. Petroleum Geologists Bul1., v. 37, p. 114-124.

Seitz, Frederick, 1952, Imperfections in nearly perfect crystals: A synthesis, in Shockley, William, and others, eds., Imperfections in nearly perfect crystals, Symposium held at Pocono Manor, October 12-14, 1950: New York, John Wiley and Sons, Inc., $490 \mathrm{p}$.

Zeller, E. J., Wray, J. I., and Daniels, Farrington, 1957, Factors in age determination of carbonate sediments by thermoluminescence: Am. Assoc. Petroleum Geologist5" Bul1., v. 41, p. 121-129. 